\title{
Fetal echocardiography in detecting anomalous pulmonary venous connection: four false positive
}

\section{cases} Marco Papa, Chiara Camesasca, Francesco Santoro, Elena Zoia, Gabriele Fragasso,
Salvatore Giannico, Sergio L Chierchia

\begin{abstract}
Prenatal detection of congenital heart disease is possible from the 16th week of pregnancy, the ideal time being the midtrimester, when most cardiac abnormalities can be detected. However, identification of anomalous pulmonary venous connection is difficult before birth and the sensitivity of fetal echocardiography in detecting this anomaly is low. Four cases are reported in which fetal echocardiographic findings obtained during the third trimester of pregnancy were highly suggestive of anomalous pulmonary venous connection. Right ventricular and atrial dominance associated with an enlarged coronary sinus or dilated superior vena cava were identified and considered to be indirect markers of the anomaly. No other cardiac anomaly was detectable. In all cases right ventricular and atrial dominance with dilated coronary sinus or superior vena cava were confirmed after birth despite the presence of normal pulmonary venous connections. These results confirm that the prenatal detection of this condition is difficult and should be based on the direct visualisation of anomalous pulmonary venous connections. The sole detection of indirect signs, such as right atrial and ventricular dominance with or without a dilated coronary sinus, superior vena cava, or inferior vena cava, does not warrant the diagnosis of anomalous pulmonary venous connection. Since the pulmonary venous flow in the human fetus is not as small as is commonly assumed, an anomalous drainage should be detectable when present and therefore should be specifically sought if the anomaly is suspected. The reasons for the presence of such transient cardiac anomalies remain obscure, but they might be related to functional or morphological rearrangement of the heart during fetal and perinatal life.
\end{abstract}

(Br Heart f 1995;73:355-358)

Keywords: fetal echocardiography, anomalous pulmonary venous connection, right ventricular dominance, enlarged coronary sinus and superior vena cava

The accuracy of fetal echocardiography in diagnosing cardiac malformations has been previously described. ${ }^{1-4}$ Four chamber and short axis views, enabling visualisation of the great arteries, greatly improve the assessment of fetal heart anatomy and function..$^{5-7}$ To obtain good quality images, the examination is usually performed between the 16th and the last eight weeks of pregnancy. ${ }^{48}$ The ideal time for screening is during the midtrimester, when all routine cross sectional views are easily obtainable. ${ }^{579}$

The prenatal diagnosis of anomalous pulmonary venous connection, however, remains difficult. ${ }^{510}$ The finding of right atrial and ventricular dominance dilatation of the superior or inferior vena cava or the coronary sinus are considered, during postnatal life, to be indirect echocardiographic criteria for anomalous pulmonary venous connection. ${ }^{11}$ During fetal life blood flow in the pulmonary veins is low, so these indirect criteria are rarely found before birth. Conversely, when found they may suggest anomalous pulmonary venous connection. ${ }^{12}$

Although some authors have emphasised the low sensitivity of fetal echocardiography in detecting anomalous pulmonary venous connection, ${ }^{510}$ the possibility of overdiagnosing this condition before birth has not, to our knowledge, been discussed. We describe four cases in which anomalous pulmonary venous connection was suspected on the basis of right atrial and ventricular dominance and a dilated coronary sinus or superior vena cava on fetal echocardiography in the last week of pregnancy.

\section{Patients and methods}

Between September 1991 and September 1993, 103 pregnant women underwent fetal echocardiography for assessment of fetal congenital heart disease that had been suspected during a routine obstetric scan.

Congenital heart disease was diagnosed in 15 fetuses and was subsequently confirmed by postnatal echocardiography, by cardiac catheterisation, at surgery, or at postmortem examination (table 1). Six fetuses, however, were erroneously diagnosed as having cardiac malformation (table 2). We describe further those false positive cases of anomalous pulmonary venous connection.

Two fetuses had right ventricular dominance and a dilated right atrium and coronary sinus, and the other two had analogous ventricular and atrial disproportion and a dilated superior vena cava. All four were found to be normal after birth, and cardiac cavities and vessels were completely normal within six months. 
Table 1 Congenital heart disease diagnosed prenatally

\begin{tabular}{|c|c|c|c|}
\hline Anomaly & $\begin{array}{l}\text { Total } \\
(n)\end{array}$ & $\begin{array}{l}\text { Associated cardiac anomalies } \\
\text { (cases) }\end{array}$ & $\begin{array}{l}\text { Associated extracardiac anomalies } \\
\text { (cases) }\end{array}$ \\
\hline $\begin{array}{l}\text { Hypoplastic left heart syndrome } \\
\text { Double outlet right ventricle }\end{array}$ & $\begin{array}{l}3 \\
3\end{array}$ & \multirow{2}{*}{$\begin{array}{l}\text { Transposition of the great } \\
\text { arteries (1) }\end{array}$} & $\begin{array}{l}\text { Turner syndrome }(1) \\
\text { Trisomy } 18, \text { Edwards syndrome (1) }\end{array}$ \\
\hline $\begin{array}{l}\text { Complete atrioventricular canal } \\
\text { Rhabdomyoma }\end{array}$ & \multirow{3}{*}{$\begin{array}{l}2 \\
2 \\
2 \\
1 \\
1 \\
1\end{array}$} & & Trisomy 21 , Down syndrome (1) \\
\hline $\begin{array}{l}\text { Tetralogy of Fallot } \\
\text { Partial atrioventricular canal } \\
\text { Ventricular septal defect }\end{array}$ & & $\begin{array}{l}\text { Absent pulmonary valve (1) } \\
\text { Right ventricular dominance (1) }\end{array}$ & \multirow{2}{*}{$\begin{array}{l}\text { Trisomy } 21 \text {, Down syndrome (1) } \\
\text { Trisomy } 21 \text {, Down syndrome (1) } \\
\text { Trisomy } 21 \text {, Down syndrome (1) } \\
\text { Cleft lip and palate (1) }\end{array}$} \\
\hline Right atrial isomerism & & $\begin{array}{l}\text { Complete atrioventricular } \\
\text { canal, single ventricle, } \\
\text { double outlet right ventricle, } \\
\text { pulmonary stenosis (1) }\end{array}$ & \\
\hline
\end{tabular}

Table 2 Cases wrongly diagnosed as having congenital heart disease

\begin{tabular}{lll}
\hline Diagnosis & Factors possibly contributing to error & Associated features \\
\hline Perimembranous ventricular septal defect & $\begin{array}{l}\text { One examination, early pregnancy } \\
\text { (18 weeks' gestation) }\end{array}$ & Trisomy 18, Edwards syndrome \\
Aortic coarctation & $\begin{array}{l}\text { Right ventricular dominance } \\
\text { Right ventricular dominance, right atrial and } \\
\text { superior vena cava enlargement } \\
\text { connection pulmonary venous }\end{array}$ & \\
$\begin{array}{l}\text { Anomalous pulmonary vena cava } \\
\text { in superior vena cava }\end{array}$ & $\begin{array}{l}\text { Right ventricular dominance, right atrial and } \\
\text { superior vena cava enlargement } \\
\text { Right ventricular dominance, right atrial and } \\
\text { coronary sinus enlargement } \\
\text { Right ventricular dominance, right atrial and } \\
\text { Anomalous pulmonary venous connection } \\
\text { in coronary sinus }\end{array}$ & \\
\hline
\end{tabular}

Fetal echocardiography was performed between the 30th and the 37 th week of gestation using 3.5 or $5.0 \mathrm{MHz}$ transducers (model 77020 AC, Hewlett-Packard, Andover, MA). Echocardiography was performed in the standard four chamber, long axis, and short axis views. Specific views for imaging the aortic arch, the ductus arteriosus, and, when possible, the pulmonary veins were also obtained. All studies were videotaped and available for review.

\section{CASE REPORTS}

Two women aged 25 and 26 were referred on the 31 st and 36th week of gestation because a routine scan showed ventricular disproportion in their fetuses. One fetus additionally showed hepatomegaly, the other had been one of twins.

Fetal echocardiography showed right ventricular and atrial dominance, dilated coronary sinus (figure 1), and a normal patent foramen ovale and ductus arteriosus. Blood flow was normal into and out of the heart and in the aortic arch. A persistent superior left vena cava was not evident.

A total anomalous pulmonary venous connection in the coronary sinus was suspected, although pulmonary venous connections were not visualised because of the unfavourable fetal positions.

In the first case an additional scan was performed at 33 weeks to assess the pulmonary venous connections. Right ventricular and atrial dominance and enlargement of the coronary sinus were confirmed. No other malformations were shown; the two left pulmonary veins were normally connected to the left atrium. A partial anomalous pulmonary venous connection in the coronary sinus was suspected.
A boy of $2300 \mathrm{~g}$ and a girl of $3600 \mathrm{~g}$ were delivered normally at the 36th and 39th weeks of pregnancy respectively. Transthoracic echocardiography was performed at birth, confirming right ventricular and atrial dominance and enlargement of the coronary sinus but also normal pulmonary venous connections in both babies.

Follow up echocardiography at 2 weeks showed that the diameters of the right ventricle, right atrium, and coronary sinus were normal in one of them. The presence of a persistent superior left vena cava was excluded. In the boy the left superior vena cava remained connected to the coronary sinus. Dilatation of the right ventricle, right atrium, and coronary sinus persisted until 3 months of age, but at 6 months the persistent left superior vena cava was no longer detectable.

Two other women aged 23 and 28 were referred to our unit for fetal echocardiography because ventricular disproportion was found during a routine scan performed to assess fetal growth at the 30th and 37th weeks of pregnancy, respectively. The fetuses showed compression of the left ventricle by an enlarged right ventricle and dilated right atrium and superior vena cava. No images of the pulmonary veins were seen on the sector scan. A normally patent foramen ovale was evident. Aortic, pulmonary, and atrioventricular valves were normal, as were the aortic arch and ductus arteriosus. On the basis of these indirect criteria a total anomalous pulmonary venous connection to the superior vena cava was suspected in both fetuses.

Two boys of $2700 \mathrm{~g}$ and $3100 \mathrm{~g}$ were delivered normally at term. Echocardiography performed after birth showed a right ventricular and atrial dominance, a patent foramen ovale with a left to right shunt, and normal 
Top: Four chamber cross sectional echocardiographic examination in a fetus with right ventricular dominance and enlargement of the coronary sinus. Bottom: Short axis view shows coronary sinus enlargement and atrial disproportion. $C S$, coronary sinus; $L A$, left atrium; $L V$, left ventricle; $R A$, right atrium; $R V$, right ventricle.
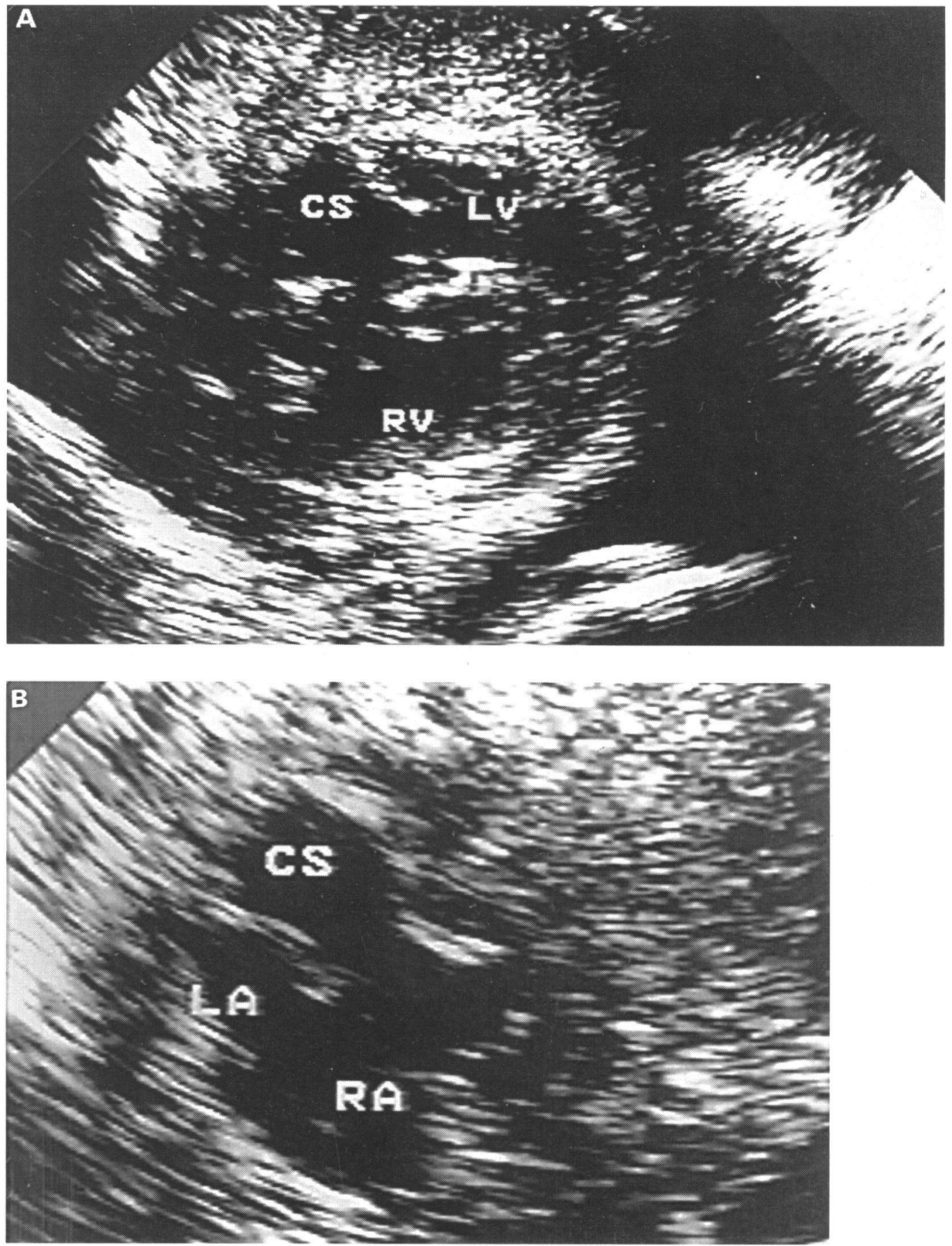

pulmonary venous connections. Additionally, a mild dilatation of the superior vena cava was confirmed in both. Aortic coarctation and pulmonary stenosis were excluded. At two weeks of age the sizes of the right ventricle, right atrium, and superior vena cava were within the normal range in both cases.

\section{Discussion}

The prenatal detection of congenital heart disease is feasible, and most common heart malformations can be detected by fetal echocardiography. Nevertheless, some important conditions such as atrial septal defect, aortic coarctation, total anomalous pulmonary venous connection, and muscular ventricular septal defects are often missed. ${ }^{51013}$
Overdiagnosis is rarely reported and is often related to ventricular disproportion, which may falsely lead to a diagnosis of aortic stenosis, aortic coarctation, aortic hypoplasia, and ventricular septal defects. ${ }^{49101314}$ To our knowledge, however, the possibility of overdiagnosing anomalous pulmonary venous connection by fetal echocardiography has never been reported.

In all our cases the right ventricular dominance and the enlargement of the right atrium and coronary sinus or superior vena cava, observed during the third trimester of pregnancy, subsequently became normal.

Therefore, although ventricular disproportion in postnatal life may suggest congenital heart disease, this is not the rule in the fetus, 
especially when pulmonary venous drainage cannot be identified.

Indeed, since the pulmonary venous flow in human fetuses is not as small as is commonly assumed, an anomalous drainage should be detectable when present and therefore should be specifically sought if anomalous pulmonary venous connection is suspected. This approach seems particularly opportune when isolated right ventricular dominance is the only abnormal finding (table 2). Transient structural or haemodynamic events, or both, can result in such dominance and lead to misdiagnosis. The reasons for the presence of such indirect signs remain obscure, but they might be related to functional or morphological changes in the heart during fetal and perinatal life.

In conclusion, we confirm the difficulty in detecting anomalous pulmonary venous connection prenatally. In our opinion, the prenatal diagnosis of this abnormality can be established only when complete visualisation of anomalous pulmonary venous connections is obtained. Indirect echocardiographic criteria, such as right ventricular and atrial dominance and dilated coronary sinus or superior vena cava, serve only to support the diagnosis.

1 Kleinman CS, Hobbins JC, Jaffee CC, Lynch DC, Talne NS. Echocardiographic studies of the human fetus: prenatal diagnosis of congenital heart disease and cardiac dysrhythmias. Pediatrics 1980;65:1059-67.
2 De Vore GR, Donnerstein RL, Kleinman CS, Platt LD, Hobbins JC. Fetal echocardiography. I. Normal anatomy as determined by real-time-directed M-mode ultrasound. Am f Obstet Gynecol 1982;144:249-60.

3 De Vore GR. Fetal echocardiography-a new frontier. Clin Obstet Gynecol 1984;27:359-77.

4 Allan LD, Crawford DC, Anderson RH, Tynan MJ. Echocardiographic and anatomical correlations in feta congenital heart disease. Br Heart $\mathcal{f}$ 1984;52:542-8.

5 Benacerraf BR, Pober BR, Sanders SP. Accuracy of fetal echocardiography. Radiology 1987;165:847-9.

6 Allan LD, Crawford DC, Chita SK, Tynan MJ. Prenatal screening for congenital heart disease. $B M \mathcal{F}$ 1986;292: 1717-9.

7 Lange LW, Sahn DJ, Allen HD, Goldberg SJ, Anderson C, Giles H. Qualitative real-time cross-sectional echocardiographic imaging of the human fetus during the second half of pregnancy. Circulation 1980;62: 799-86.

8 Tan J, Silverman NH, Hoffman JIE, Vilegas M, Schmidt KG. Cardiac dimension determined by cross-sectional echocardiography in the normal human fetus from 18 weeks to term. Am $\mathcal{F}$ Cardiol 1992;70:1459-67.

9 Marasini M, Cordone M, Pongiglione G, Lituania M Bertolini A, Ribaldone D. In utero ultrasound diagnosis of congenital heart disease. $₹$ Clin Ultrasound 1988; 16:103-7.

10 Allan LD, Chita SK, Sharland GK, Fagg NLK, Anderson RH, Crawford DC. The accuracy of fetal echocardiography in the diagnosis of congenital disease. Int $\mathfrak{f}$ graphy in the diagnosis
Cardiol 1989;25:279-88.

11 Lucas RV, Krabill KA. Anomalous venous connections, pulmonary and systemic. In: Adams $\mathrm{FH}$ pulmonary and systemic. In: Adams FH, heart disease in infants children and adolescents. heart disease in infants, children, and

12 Nyberg DA, Emerson DS. Cardiac malformations. In Nyberg DA, Mahony BS, Pretorius DH, eds. Diagnostic ultrasound of fetal anomalies. Text and atlas. Chicago: Year Book Medical Publishers, 1990:330.

13 Crawford DC, Chita SK, Allan LD. Prenatal detection of congenital heart disease: factors affecting obstetric management and survival. Am f Obstet Gynecol 1988; 159:352-6.

14 Copel JA, Pilu GL, Gren J, Hobbins JC, Kleinman CS Fetal echocardiographic screening for congenital heart disease: the importance of the four-chamber view. $A m \mathcal{F}$ Obstet Gynecol 1987;157:648--55. 